\title{
ARTIGOS
}

\section{JONGO E EDUCAÇÃO ESCOLAR QUILOMBOLA: DIÁLOGOS NO CAMPO DO CURRÍCULO}

\author{
KALYLA MAROUN
}

\begin{abstract}
RESUMO
Este artigo tem como objetivo analisar alguns diálogos, no campo do currículo, entre o jongo - prática cultural afro-brasileira - e a Educação Escolar Quilombola - nova modalidade de ensino institucionalizada no Brasil - a partir de um estudo de caso em uma comunidade quilombola (Santa Rita do Bracuí), localizada na região sul do estado do Rio de Janeiro, no município de Angra dos Reis. Para tanto, foi realizado um trabalho de campo de cunho etnográfico ao longo de dois anos, na perspectiva de uma descrição densa. Percebemos que as crianças e jovens quilombolas vêm construindo suas identidades étnicas por meio da inserção na prática do jongo, o que vem contribuindo e legitimando a demanda das lideranças políticas de Bracuí pela entrada dessa prática no currículo da escola local.
\end{abstract}

ENSINO • CURRÍCULOS • QUILOMBOS • CULTURA AFRO-BRASILEIRA

\section{JONGO AND QUILOMBOLA SCHOOL EDUCATION: DIALOGUES IN THE FIELD OF CURRICULUM}

\section{ABSTRACT}

This article aims to analyze some dialogues, in the field of curriculum between the jongo, an Afro-Brazilian cultural practice, and Quilombola School Education, a new teaching method institutionalized in Brazil, based on a case study in a quilombola community (Santa Rita do Bracuí) located in the southern region of the state of Rio de Janeiro in the municipality of Angra dos Reis. In order to do this, fieldwork employing ethnographic methods with the prospect of a thorough description, was conducted for two years. We realized that quilombola children and youth have been building their ethnic identities through their insertion in the practice of jongo, contributing and legitimizing the demand of the political leaders of Bracuí to introduce this practice into the local school curriculum. 
Cet article a pour objectif d'analyser quelques dialogues, dans le domaine des curriculum scolaire, entre le jongo - pratique culturelle afro-brésilienne et l'Éducation Scolaire Quilombola - nouvelle modalité d'enseignement institutionnalisée au Brésil - à partir d'une étude de cas dans une communauté quilombola (Santa Rita do Bracuí), située dans la région de l'État de Rio de Janeiro, dans la municipalité de Angra dos Reis. Pour autant, nous avons réalisé un travail de champ de caractère ethnographique au long de deux ans, sous la perspective d'une dense description. Nous nous sommes apperçus que les enfants et les jeunes quilombolas construisent leurs identités ethniques au moyen de l'insertion de la pratique du jongo, ce qui contribue et légitime la demande, de la part des dirigeants politiques de Bracuí, de l'entrée de cette pratique dans le curriculum scolaire local.

ENSEIGNEMENT • CURRICULUM SCOLAIRE • QUILOMBOS •

CULTURE AFRO-BRÉSILIENNE

\section{JONGO Y EDUCACIÓN ESCOLAR QUILOMBOLA: DIÁLOGOS EN EL ÁMBITO DEL CURRÍCULO}

RESUMEN

Este artículo tiene el objetivo de analizar algunos diálogos, en el ámbito del currículo, entre el jongo -práctica cultural afrobrasileña-y la Educación Escolar Quilombola -nueva modalidad de enseñanza institucionalizada en Brasil- a partir de un estudio de caso en una comunidad quilombola (Santa Rita do Bracuí), ubicada en la región sur del estado de Rio de Janeiro, en el municipio de Angra dos Reis. Para ello se llevó a cabo un trabajo de campo de cuño etnográfico a lo largo de dos años, desde la perspectiva de una descripción densa. Percibimos que los niños y jóvenes quilombolas vienen construyendo sus identidades étnicas por medio de la inserción en la práctica del jongo, lo que ha contribuido para legitimar la demanda de los liderazgos políticos de Bracuí por el ingreso de esta práctica en el currículo de la escuela local. 


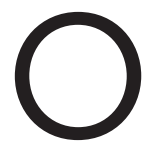

GOVERNO BRASILEIRO, PRINCIPALMENTE A PARTIR DE 2003, INTRODUZIU, NO DEBATE

político e em seus programas e ações, a temática da diversidade na educação. As políticas de diversidade conquistaram visibilidade dentro do espaço político-governamental e, com base nelas, foram sancionadas algumas leis, dentre as quais destacamos a Lei Federal n. 10.639, de 2003, e suas respectivas Diretrizes Curriculares (BRASIL, 2004), que tornam obrigatório o ensino da história e da cultura afro-brasileira e africana na educação básica. Tais iniciativas, junto a outras ações e circunstâncias, ${ }^{1}$ possibilitaram a ampliação do debate público e acadêmico acerca da educação em comunidades quilombolas, contribuindo para reflexões e

Como a criação da Secretaria de Políticas de Promoção da Igualdade Racial - Seppir - em 2003, e da Secretaria de Educação Continuada Alfabetização e Diversidade - Secad -, em 2004, a qual, desde 2001, passou a designar-se Secretaria de Educação Continuada, Alfabetização, Diversidade e Inclusão - Secadi.

Nesse mesmo evento

foi instituída uma comissão quilombola de assessoramento à comissão

especial da Câmara de Educação Básica, formada por oito integrantes, entre quilombolas, acadêmicos representantes do governo. demandas no intuito de trazer legitimação para a entrada de seus saberes, culturas e tradições nos currículos escolares.

Visto que a Lei n. 10.639, de 2003, apesar de instituir o ensino da cultura e história afro-brasileira e africana, não tratou das especificidades da educação quilombola, em maio de 2010, durante a Conferência Nacional de Educação - Conae -, ficou evidenciada a necessidade de formulação de políticas educacionais específicas para atender às demandas das comunidades quilombolas. Nesse sentido, ainda em 2010, no mês de novembro, realizou-se em Brasília o I Seminário Nacional de Educação Quilombola, ${ }^{2}$ cujo objetivo foi construir os alicerces do Plano Nacional de Educação Quilombola, e subsidiar o Conselho Nacional de Educação na produção das Diretrizes Curriculares Nacionais para Educação Escolar Quilombola. Em 14 de dezembro de 2010, foi publicada a Resolução 
n. 7 do Conselho Nacional de Educação - Educação/Câmara de Educação Básica - CNE/CEB -, que, ao fixar Diretrizes Curriculares Nacionais para o ensino fundamental de nove anos, inclui as especificidades da Educação Escolar Quilombola:

\begin{abstract}
Art. 39 - A Educação Escolar Indígena e a Educação Escolar Quilombola são, respectivamente, oferecidas em unidades educacionais inscritas em suas terras e culturas e, para essas populações, estão assegurados direitos específicos na Constituição Federal que Ihes permitem valorizar e preservar as suas culturas e reafirmar o seu pertencimento étnico.
\end{abstract}

A partir das deliberações da Conferência Nacional de Educação (CONAE, 2010), e em atendimento às Resoluções n. 07/2010 e n. 04/2010 do CNE/CEB - esta última institui as Diretrizes Curriculares Gerais para a Educação Básica -, a Câmara de Educação Básica do Conselho Nacional de Educação institui uma Comissão responsável pela elaboração das Diretrizes Curriculares Nacionais para a Educação Escolar Quilombola. Assim, as Diretrizes, aprovadas em junho de 2012 e homologadas pelo então Ministro da Educação em novembro do mesmo ano, têm a função de orientar os sistemas de ensino para que eles possam implementar a Educação Escolar Quilombola, mantendo um diálogo com a realidade sociocultural e política das comunidades e dos movimentos sociais.

Desse modo, podemos dizer que o debate sobre o tema da educação escolar em comunidades remanescentes de quilombo se sustenta, no plano normativo, em ao menos seis documentos, a saber: a Lei Federal n. 10.639, de 2003; a Convenção 169 da Organização Internacional do Trabalho - OIT -, promulgada pelo Decreto Federal n. 5.051, de 2004, que garante o direito de uma educação apropriada às diferenças das populações étnicas; o Plano Nacional de Desenvolvimento de Populações Tradicionais (Decreto n. 6.040, de 2007), que aponta para a necessidade de se produzirem modalidades de educação adequadas aos modos de vida das populações tradicionais; a Resolução n. 7/2010, do CNE/CEB, que avança na garantia de uma "educação diferenciada" ao mencionar a necessidade de respeito, por parte das escolas que atendem às populações do campo, comunidades indígenas e quilombolas, para com suas peculiaridades de modos de vida. Além disso, essa mesma Resolução recomenda a utilização de pedagogias condizentes com as suas formas próprias de produzir conhecimentos; a Resolução n. 4/2010, do CNE/CEB, que institui as diretrizes gerais para a Educação Básica e faz menção na secção VII especificamente à Educação Escolar Quilombola; e, finalmente, as Diretrizes Curriculares Nacionais para a Educação Escolar Quilombola (BRASIL, 2012). De acordo com este último documento citado, a categoria Educação Escolar Quilombola se destina tanto à educação 
formal oferecida em escolas localizadas em territórios quilombolas, como àquela ofertada em escolas que atendem alunos oriundos destes. As escolas situadas nos limites do território quilombola são classificadas pela referida legislação como escolas quilombolas. Portanto, o ensino nas escolas localizadas em comunidades quilombolas, ou que atendam

Para um aprofundamento sobre a descrição dos processos de ressignificação do jongo a partir do seu reavivamento na comunidade, sugerimos a leitura do trabalho de Maroun (2013). Neste a autora descreve caracteriza três momentos diferentes do jongo em Bracuí, que abarcam período compreendido entre o final da década de 1990 e os dias atuais. São eles: jongo renascido quando, no final da década de 1990, as crianças e jovens são convidados a dançar o jongo com velhos jongueiros que o retomam informalmente na comunidade; jongo de formação - quando, em 2005, iniciam-se as oficinas

de jongo, com o intuito de inserir um número maio de crianças e jovens nessa prática, o que ocorre por meio de um projeto de educação não formal intitulado "Pelos Caminhos do Jongo", submetido e gerenciado pela própria comunidade; jongo de apresentação - em que o papel do jongo passa a ser o de visibilidade política (re)afirmação identitária para além da comunidade dos próprios quilombolas.

Foram sete viagens à comunidade, com períodos de estadia que variaram entre três e nove dias, entre 2011 e 2012. Em todos eles,

fiquei abrigada na casa de uma das lideranças políticas - Marilda de Souza Francisco -, que é também zeladora da escola Áurea Pires da Gama desde a década de 1990. O trabalho de campo contou com etnografia das rodas de jongo do Bracuí, e com entrevistas com as lideranças políticas os velhos jongueiros ainda vivos, e os jovens jongueiros. A relação da comunidade com a escola local foi analisada sob o olhar dos quilombolas,

tendo como foco a demanda apresentada pelos mesmos por uma "educação diferenciada". alunos oriundos destas, deve ser alimentado e fundamentado pelos seguintes eixos: a) memória coletiva; b) línguas reminiscentes; c) marcos civilizatórios; d) práticas culturais; e) tecnologias e formas de produção do trabalho; f) acervos e repertórios orais; g) festejos, usos, tradições e demais elementos que conformam o patrimônio cultural das comunidades quilombolas de todo o país.

A partir da conjuntura apresentada, voltamo-nos ao jongo na comunidade quilombola de Santa Rita do Bracuí, sobre a qual discorreremos mais adiante. Nesta, observamos recentes processos de ressignificação dessa prática cultural no final da década de 1990, intensificados na primeira década do século XXI. ${ }^{3}$ É por meio do jongo que as crianças e jovens quilombolas de Santa Rita do Bracuí vêm delimitando as fronteiras sociais que os diferenciam dos "outros" e os legitimam enquanto grupo étnico (BARTH, 2000); isto é, a partir da inserção no jongo, eles constroem e, por conseguinte, reafirmam suas identidades quilombolas.

Diante do exposto, o presente artigo tem como objetivo analisar alguns diálogos possíveis, no campo do currículo, entre o jongo - prática cultural de origem afro-brasileira - e a Educação Escolar Quilombola nova modalidade de ensino institucionalizada no Brasil -, a partir de um estudo de caso realizado em uma comunidade remanescente de quilombo, localizada na região sul do estado do Rio de Janeiro, no município de Angra dos Reis, cujo nome é Santa Rita do Bracuí. Na comunidade, localiza-se a escola municipal Áurea Pires da Gama. Pretendemos traçar aqui um diálogo frutífero, que possa ultrapassar as relações observadas entre educação escolar quilombola e jongo, no interior da comunidade citada, contribuindo para uma reflexão sobre a educação escolar em áreas remanescentes de quilombo, ou que atendam alunos oriundos desses territórios, com foco na relação entre saberes tradicionais, desenvolvidos e ressignificados no interior do grupo, e os saberes escolares, que compõem os denominados conteúdos clássicos. Ousamos também dizer que a análise aqui pretendida, na perspectiva de uma teoria pós-crítica do currículo (SILVA, 2010), traz elementos para pensarmos nos processos de dominação dos saberes escolares, centrados no silenciamento e na invisibilidade das questões voltadas às relações étnico-raciais.

O desenvolvimento do trabalho de campo foi pautado na interface da antropologia com a educação. A opção teórico-metodológica para o acúmulo de dados foi a etnografia, que diz respeito à descrição, observação e trabalho de imersão no campo, realizada ao longo de dois anos. ${ }^{4}$ Predominaram nesta pesquisa as vertentes interpretativista $e$ 
culturalista da etnografia de Geertz (1989), já que há uma busca não pelas leis e regras que regem a comunidade, mas sim pelo aspecto simbólico relacionado à cultura, ou seja, há uma descrição densa. Nesse sentido, olhamos cuidadosamente para o processo de construção identitária por meio do jongo no interior da comunidade entre crianças e jovens quilombolas, compreendendo que, ao reafirmarem seu pertencimento étnico, contribuem para a legitimação da luta por uma "educação diferenciada”. Para a análise dos dados empíricos acumulados, debruçamo-nos sobre os conceitos de identidade étnica (BARTH, 2000), comunidade quilombola (ARRUTI; FIGUEIREDO, 2005), Educação Escolar Quilombola (BRASIL, 2012) e currículo (SILVA, 2010).

\section{CAMPO DA PESQUISA: O QUILOMBO SANTA RITA DO BRACUÍ}

Inicialmente, cabe trazermos uma conceituação para o termo quilombo. Este vem sendo submetido a constantes mudanças de significados, desde a sua primeira utilização, no período colonial, tendo respondido a questões políticas diversificadas. Interessa-nos aqui a compreensão do que seria o conceito contemporâneo de quilombo ${ }^{5}$ (ARRUTI, 2008). Os quilombos, ou comunidades quilombolas, são comunidades descendentes de escravos que possuem um tipo organizacional específico, com sua territorialidade caracterizada por um uso comum, em que se ocupa o espaço com base em laços de parentesco, assentados em relações de solidariedade e reciprocidade (ARRUTI; FIGUEREDO, 2005). O principal e primeiro marco que originou essa conceituação foi o Artigo 68 da Constituição Federal de $1988 .^{6}$ Tal artigo viria com o intuito de reparar os prejuízos trazidos pelo processo de escravidão e por uma abolição que não foi acompanhada de nenhuma forma de compensação, como o acesso à terra.

Em Santa Rita do Bracuí, com a abolição da escravatura, os descendentes de escravos permaneceram nas terras da Fazenda Santa Rita, que foram doadas a eles formalmente pelo fazendeiro Comendador José de Souza Breves, por meio do seu testamento, elaborado onze anos antes do fim da escravidão, em 1877.

Não há um consenso sobre dados quantitativos a respeito dessa população. Nem mesmo o laudo e/ou o relatório antropológico (BRAGATTO, 1999; MATTOS et al., 2009), sobre os quais nos debruçamos, fornecem informações sobre o número de famílias que atualmente ocupam a área, tampouco sobre o tamanho do território, uma vez que muitas terras foram perdidas devido a conflitos fundiários que vêm assolando a comunidade. Tem-se a informação de que muitas famílias foram pressionadas a abandonar ou vender suas terras, tendo recebido pequenas indenizações. Outras optaram por vendê-las por conta própria, por

5

Para maiores informações sobre os processos de ressemantização do termo quilombo, desde o período colonial até os dias atuais, ver Arruti (2008).

6

"Aos remanescentes das comunidades dos quilombos que estejam ocupando suas terras é reconhecida a propriedade definitiva, devendo o Estado emitir-Ihes os títulos respectivos". 
vezes informalmente e sem a legalidade própria que a ação de compra e venda sugere.

Marilda afirma que o número de famílias do quilombo de Bracuí gira em torno de 380. Entretanto, essa informação é repassada com a ressalva de que tal número pode ser ainda superior, já que algumas famílias, apesar de não morarem mais no quilombo, têm também direito à terra. Logo, essa imprecisão quanto aos que não mais estão no território pode ter gerado um valor subestimado durante a pesquisa que os próprios moradores realizaram.

Bracuí é reconhecida como uma comunidade de resistência jongueira tanto pelo poder público local, ${ }^{7}$ como pelo movimento jongueiro do sudeste. Tal título lhe é conferido também pelas comunidades quilombolas de municípios vizinhos, uma vez que foi por meio do movimento jongueiro realizado no interior de Bracuí que outras comunidades, a exemplo da comunidade quilombola Campinho da Independência, situada no município de Paraty, puderam alavancar o processo de reavivamento do jongo: "A gente só consegue resgatar o jongo porque o quilombo do Bracuí é uma comunidade de resistência jongueira" (fala de uma liderança política integrante da Associação de Moradores do Quilombo do Campinho - AMOCQ -, novembro de 2011). Um dado que representa essa fala é que, como não havia memória em torno do jongo, nem mesmo velhos jongueiros ainda vivos em Campinho, foram jovens jongueiros de Bracuí os responsáveis, inicialmente, por ensinar as crianças e jovens a dançá-lo na comunidade vizinha.

Como descrevem Mattos e colaboradores (2009), em Santa Rita do Bracuí, descendentes de escravos, através da tradição oral e de memórias familiares, que incluem as narrativas sobre o jongo, não visibilizadas antes através dos canais locais e regionais de divulgação, constroem atualmente suas identidades como remanescentes de quilombo a partir do reconhecimento do patrimônio cultural que constituíram historicamente.

Desse modo, a autoidentificação como quilombola na comunidade pesquisada está diretamente relacionada a duas questões centrais. De um lado, há um processo de reconhecimento positivo de sua identidade enquanto tal - ao menos por grande parte do grupo. Do outro, assistimos à reafirmação e valorização de suas práticas culturais, a exemplo do que ocorre com o jongo. Para retratar o exposto, lançamos mão da fala de uma das lideranças políticas que integra a Associação dos diante de alguns embates políticos, a prefeitura de Angra dos Reis costuma convidar o jongo do Bracu para se apresentar no centro histórico em datas comemorativas que fazem alusão à cultura negra, como 20 de novembro o 13 de maio. Remanescentes do Quilombo de Santa Rita do Bracuí - Arquisabra. Ao ser perguntado, numa entrevista realizada em abril de 2011, qual o sentido que atribuía ao jongo, ele nos diz que: 
cabeça, quando os nossos antepassados foram sequestrados, eles sabiam que não voltariam pra lá. Então, eles deixaram pra nós essa herança, esse território, deixaram um pedacinho daquela África pra nós. [...] Esse aprendizado, essa cultura, esse modo de pensar que a gente tem no quilombo. E o jongo está incluso nisso. Pra mim, o jongo é o território; pra mim, o jongo é saudar os antepassados. Pra mim, o jongo é agradecer a esses antepassados por eu ter uma raiz, por eu ter uma memória. O jongo é um bem maior, uma preciosidade que foi deixada pra nós pra gente tá sempre lembrando daqueles que se foram, daqueles que estão, e dos que estão por vir, pra que a luta nunca morra, pra nunca esquecermos quem fomos e quem nós vamos ser.

\section{OBJETO DE ANÁLISE: O JONGO EM SANTA RITA DO BRACUÍ}

Chamado de jongo, caxambu ou tambu, variação esta relacionada com a comunidade que o pratica, é concebido como uma prática cultural que integra canto, dança circular e percussão de tambores. Foi trazido para o Brasil por africanos do grupo etnolinguístico banto, chegados à costa do sudeste na primeira metade do século XIX, oriundos de países cujos nomes hoje são Angola e Moçambique (MATTOS; ABREU, 2010), consolidando-se nas senzalas de cana de açúcar e de café no sudeste brasileiro. Ele faz parte de um conjunto de danças de origem afro-brasileira (como o batuque paulista, o candombe mineiro, o tambor de crioula do Maranhão e o zambê do Rio grande do Norte) que possuem alguns elementos comuns, dentre os quais se destacam: o uso de tambores; ${ }^{8}$ um estilo vocal composto por frases curtas cantadas por um solista e repetidas pelos outros participantes; e a presença da umbigada, que é um movimento corporal na dança em que os dançarinos encostam o ventre (PACHECO, 2007). Slenes (2007), ao buscar as relações de parentesco do jongo com práticas culturais da África, destaca que a dança de casais ao centro da roda foi descrita por viajantes no interior de Luanda e no sudoeste de Angola, no século XIX. Ainda segundo o autor, o canto e os versos com interação de solistas com o coro, no qual aqueles chamam e este responde, nos momentos de trabalho ou diversão, representavam um traço típico das canções observadas na região do antigo reino do Congo - norte da atual Angola - no mesmo período citado.

No período da escravidão, o jongo foi uma forma de comunicação dos negros, que, por meio dos pontos enigmáticos ou cifrados (metáforas que apenas eles compreendiam), expressavam uma poética e complexa forma de resistência, um espaço para exercitarem sua sociabilidade em meio à situação de cativeiro (PEREZ, 2005). Para exemplificar, tais pontos podem ser considerados análogos ao que concebemos S, número de instrumentos e o modo de combiná-los variam de comunidade para comunidade. Em geral, são utilizados tambores (tambu ou caxambu - tambor maior e o candongueiro tambor menor) e puítas (um ancestral da cuíca) de tamanhos e materiais diversos. O jongo do Bracuí ocorre com apenas um tambor, o tambu ou caxambu. 
por provérbios e tratam metaforicamente da vida da comunidade, além de serem utilizados para resolver pendências, assim como ocorre em alguns grupos étnicos da África. Para Passos (2004), como o jongo teve, desde as senzalas, a função de sociabilização dos indivíduos vigiados e proibidos de se expressar, estes criaram maneiras de dizer, por meio de metáforas, aquilo que só eles poderiam entender.

Segundo Costa (2011), no período pós-abolição, a expectativa do caos intensificou a perseguição aos batuques, já que, para a população em geral, estes eram similares ao ritmo das religiões afro-brasileiras. Em sua pesquisa sobre a migração de descendentes de escravos para a região da Baixada Fluminense, ao longo do século XX, o autor enfatiza o preconceito sofrido pelo jongo nesse processo migratório, tomado como "macumba”, o que colaborou para seu desaparecimento.

Para Mattos e Abreu (2007), só entre os anos de 1960 e 1970 é que folcloristas, sociólogos e antropólogos intensificam o interesse pelo jongo enquanto objeto de pesquisa. Ressaltamos que, para a maioria dos estudiosos, o jongo estaria prestes a desaparecer, concomitantemente aos velhos jongueiros que ainda o praticavam, uma vez que as crianças e os jovens eram proibidos de participar das rodas, o que tinha como função protegê-los dos feitiços eminentes dessa prática cultural que apenas os mais experientes, os “cumbas”, dominavam.

Já na década de 1980, novas pesquisas abordaram a presença do jongo nas favelas cariocas e seu papel na origem do samba (MATTOS; ABREU, 2007), concluindo que, ao contrário das premissas iniciais, o jongo não desaparecera totalmente. Tal fato sugere novos processos de ressignificação da tradição vinculados à sua prática, como, por exemplo, a entrada de crianças e jovens nas rodas, o que pode ter tido como consequência o enfraquecimento do caráter mágico do jongo.

Na comunidade de Santa Rita do Bracuí, a memória em torno do adormecimento do jongo, ${ }^{9}$ ao longo do século XX, aponta para duas questões centrais. A primeira era o preconceito de parte dos próprios moradores, que procuravam negar sua prática em um período cujas manifestações afro-brasileiras eram rechaçadas, tanto no nível social como no político. Ser jongueiro era reafirmar uma identidade negra acoplada à representação pejorativa de "macumba", disseminada pelo senso comum. Nas palavras de outra liderança política integrante da Arquisabra: “a primeira vez que eu vi o jongo, não lembro a data certa, foi no galpão da Igreja de Santa Rita. Eu achei aquilo muito estranho. Todos os preconceitos que as pessoas tinham com relação ao jongo, eu, quando vi, também não conhecia, achei estranho" (julho de 2011). A segunda razão, que parece estar diretamente relacionada à primeira, remete à rejeição da própria juventude para com o jongo. Num contexto de crescimento e modernização da cidade de Angra dos Reis, eles o viam com bastante 
estranhamento. Nas palavras do jongueiro mais velho da comunidade: “ninguém queria saber de jongo mais não” (abril de 2011).

As falas dos velhos jongueiros ainda vivos, que acompanharam o processo de adormecimento do jongo na comunidade, apontam para alguns pontos em comum, que representam a memória criada em torno dele: a prática do jongo havia sido algo corriqueiro entre seus antepassados e, portanto, foi por eles adquirida no próprio contexto familiar; estes, enquanto crianças, não podiam participar, mas, apesar disso, cresceram imersos nessa prática cultural, que muitas vezes era acessada pela observação direta das rodas e/ou pelo discurso corrente dos familiares mais velhos. Como comenta outro velho jongueiro, “às vezes me levavam pra roda, mas eu ficava só observando... Conforme você ia ficando maiorzinho, ia se aproximando da roda, é que o pessoal ia te indicando como é que você faz pra entrar" (novembro de 2011).

Burke (1992), na tentativa de sistematizar a variedade dos meios de organização e transmissão da memória, atenta para cinco formas diferenciadas, dentre as quais enfatizamos a memória ritual, que remete às ações sociais repetitivas, como os rituais, cerimônias, bem como as técnicas corporais. Logo, a partir do reavivamento do jongo na comunidade, tais pontos comuns apresentados pelos velhos jongueiros passaram a contemplar a memória em torno de sua prática, que são transmitidos para as crianças e jovens.

O reavivamento do jongo em Bracuí se inicia no final década de 1990. Se, no passado, as crianças eram proibidas de dançar o jongo, hoje elas são maioria nas rodas, o que aponta para um processo de transmissão dessa prática, representada por iniciativas de institucionalização e/ou sistematização dos saberes tradicionais que o envolvem, a fim de que estes possam ser perpetuados. Foi no ano de 2005 que o jongo, até então apreendido e transmitido no cotidiano da comunidade, na relação dos velhos jongueiros com as crianças e jovens, nos quintais de suas casas ou no galpão da igreja, passou a ser ensinado em espaços de educação não formal - as oficinas de jongo -, o que se deu através de um projeto de educação não formal intitulado "Pelos Caminhos do Jongo", ${ }^{10}$ escrito e gerenciado pelas lideranças políticas da comunidade, que ocorria aos sábados, na casa de estuque. Mas, ainda que o jongo tenha ficado adormecido, a memória em torno dele produzida pelos velhos jongueiros e o contato destes, muitos deles ainda vivos, com as crianças da comunidade, permitiram às mesmas um processo de aprendizagem muito significativo. Quando tinham alguma dificuldade ou dúvida decorrente das práticas educativas às quais eram submetidos nas oficinas do projeto, era aos/às mestres jongueiros(as) que recorriam.

Um dado etnográfico ilustra o quanto o jongo atualmente é domínio de jovens e crianças. Na festa em homenagem à padroeira Santa Rita, realizada na própria comunidade, em maio de 2011, pudemos submetido e aprovado pela Brazil Foundation. Esta é uma organização não governamental que apoia iniciativas da sociedade civil brasileira, representativas de soluções criativas e diferenciadas para os desafios enfrentados por comunidades de todo o país. 
assistir tanto à folia de reis, como à roda de jongo do Bracuí. Enquanto aquela era formada por um seleto grupo de quilombolas de idade mais avançada, esta contou com a presença majoritária de crianças e jovens que, desde o início da festa, mostravam-se muito animados e ansiosos para a hora do jongo. Na folia, além de poucas pessoas da própria comunidade terem participado, os externos que foram prestigiar o evento também não se motivaram tanto para observá-la. Por outro lado, no jongo, além da participação massiva das crianças e jovens quilombolas, que formaram uma grande roda destacada pelas saias de chita com duas estampas floridas diferenciadas entre as meninas, e a blusa do projeto "Pelos Caminhos do Jongo" entre os meninos, o ânimo e a curiosidade de todos os presentes foram visivelmente alavancados. Além das crianças e jovens, havia apenas uma velha jongueira na roda.

Implementado o projeto "Pelos Caminhos do Jongo", Bracuí, por meio da construção e reafirmação identitária de jovens e crianças, inicia, ainda que de forma preliminar, uma organização para a permanência na luta pelo território e pelo reconhecimento através do "reavivamento de traços culturais tradicionais selecionados" (BARTH, 2000, p. 63). Como nos lembra uma das lideranças políticas da Arquisabra (agosto de 2011):

\section{[...] o jongo é o carro-chefe. Se tem o cinema hoje no quilombo, veio através do jongo [...]. O jongo veio fortalecer a comunidade, unir mais as pessoas, veio unir os jovens, veio mostrar pras pessoas a importância da cultura da comunidade.}

Os processos de transmissão e apreensão do jongo entre crianças e jovens de Bracuí ocorreram no âmbito extraescolar. A ausência da escola até aqui não é fruto do acaso. Ao analisarmos a história do jongo do Bracuí a partir do reavivamento de sua prática, percebemos que a escola não teve qualquer contribuição para a formação identitária e a valorização dos saberes tradicionais entre crianças e jovens quilombolas, que, somente por meio das oficinas ou de práticas educativas informais com seus próprios mestres, puderam apreender e valorizar sua ancestralidade, memória, corporalidade, cultura, história, oralidade. Nas palavras de uma jovem jongueira (agosto de 2011):

\section{[...] o jongo é bonito, eu gosto de dançar e é importante que as pes- soas conheçam para diminuir o preconceito. Quando a gente não conseguia fazer um ponto de jongo, ia na casa do Seu Zé Adriano (jongueiro mais velho da comunidade) pra ele ajudar a gente.}

Diante da ausência da escola no processo de construção e reafirmação identitária, o projeto "Pelos Caminhos do Jongo" se tornou uma ferramenta pedagógica indispensável à condução de uma educação que atendesse aos saberes, modos de vida e culturas quilombolas. A 
aquisição de saberes ocorreu fundamentalmente no plano da oralidade, da corporalidade, da memória, da inventividade da tradição (SAHLINS, 2004), que carregam um conjunto de representações e tradições culturais, tecendo o processo de construção de uma identidade silenciada e negada pela escola. Nesse sentido, as oficinas de jongo construíram valores em torno do orgulho e da afirmação da identidade étnica, e do sentimento de pertencimento ao grupo. Observamos, portanto, uma ampliação do conceito de educação a partir da proposição da não limitação dos processos de ensino-aprendizagem ao interior de unidades escolares formais, transpondo-os para fora dos muros da escola, ou seja, para os espaços da casa, do trabalho, do lazer, do associativismo, dentre outros (GOHN, 2011).

\section{COMUNIDADE QUILOMBOLA E ESCOLA QUILOMBOLA: APROXIMAÇÕES E AFASTAMENTOS}

Localiza-se no território quilombola de Santa Rita do Bracuí a escola municipal Áurea Pires da Gama, na estrada de Santa Rita, principal rua do quilombo, bem próximo à "pista”, ou seja, à estrada Rio-Santos. Oferece atualmente o ensino fundamental e a educação de jovens e adultos - EJA.

Apesar de localizada no território quilombola, curiosamente, até 2015, a referida escola não era classificada no censo escolar como quilombola. Mesmo compreendendo que a simples classificação atribuída pela direção escolar não implica "a existência de qualquer diferenciação na sua forma física, nos métodos pedagógicos, na sua gestão, na composição e formação dos seus professores ou nos materiais didáticos utilizados” (ARRUTI, 2011, p. 169), entendemos que há um problema político e/ou de desconhecimento por parte dos gestores no tocante à correta forma de classificar as escolas localizadas nesses territórios étnicos.

Construída no início da década de 1970 do século XX, a partir da abertura da Rio-Santos, de fato, a escola municipal Áurea Pires da Gama recebe hoje um percentual pequeno de alunos oriundos do quilombo. Apesar de a escola não possuir um cadastro que permita contabilizarmos quantos são os alunos quilombolas que lá estudam, ${ }^{11}$ há um dado estimado realizado pelas lideranças políticas de Bracuí. O resultado da pesquisa aponta que, num universo de aproximadamente mil alunos, pelo menos 95 sejam quilombolas.

A relação com a escola municipal vem sendo, desde o seu nascimento, um campo de disputa política, já que ela veio substituir um padrão de educação comunitária que atendeu quase que exclusivamente às crianças quilombolas até a década de 1970. Quem sabia ler e escrever ensinava aos outros. A educação para os quilombolas, nesse período, tinha como objetivo principal inserir os alunos na leitura e na escrita, quando não, restringia-se à assinatura do nome. aparente dificuldade dos administradores da escola em identificá-los, ou seja, eles desconhecem que critérios deveriam ser utilizados para classificá- los enquanto quilombolas ou não quilombolas. 
Segundo Marilda, que, como já mencionado, trabalha como zeladora da escola e foi também aluna e mãe de dois ex-alunos da mesma, ao longo desses quase quarenta anos de existência, um marco importante de estreitamento das relações entre a escola e a comunidade foi quando, em 2003, durante a realização da primeira edição do evento "Frutos da Terra"12 - iniciativa da comunidade, respaldada pela direção da escola -, houve uma apresentação de jongo para a comunidade escolar.

Mas, apesar de o jongo ter sido "inserido" na escola no ano de 2003, em gestões posteriores, iniciadas em 2005, houve um distanciamento da escola para com a comunidade, o que acabou por contribuir para a invisibilidade desta última no contexto escolar. O jongo e, consequentemente, a comunidade de Bracuí retornam algumas vezes para a escola, mas de forma superficial e folclorizada, apenas para contemplar as datas específicas que fazem alusão à cultura negra e para cumprir a agenda referente à Lei n. 10.639 de 2003, como se simplesmente chamar o jongo para a escola contemplasse tal política educacional. A herança da cultura africana, apesar de constituir uma importante matriz da cultura brasileira, vem ocupando uma posição marginalizada em um território cujo contexto, uma escola quilombola, pede um tratamento pedagógico totalmente diferenciado para o tema.

Tais exemplos retratados demonstram que, apesar de o jongo ter sido um elemento fundamental na construção identitária e no desenvolvimento da autoestima das crianças do quilombo do Bracuí, a escola não as reconheceu e tampouco as valorizou enquanto quilombolas. Pelo contrário, continuou a invisibilizá-las, negando-as e afastando-as de seus saberes tradicionais. Como nos demonstra Kabengele Munanga (2005, p. 16), o fato de a escola Áurea Pires da Gama receber majoritariamente alunos não quilombolas não justifica a ausência de discussões e conteúdos curriculares relativos ao saberes étnicos de seu povo:

O resgate da memória coletiva e da história da comunidade negra não interessa apenas aos alunos de ascendência negra. Interessa também aos alunos de outras ascendências étnicas, principalmente branca, pois ao receber uma educação envenenada pelos preconceitos, eles também tiveram suas estruturas psíquicas afetadas. Além disso, essa memória não pertence somente aos negros. Ela pertence a todos, tendo em vista que os segmentos étnicos que, apesar das condições desiguais nas quais se desenvolvem, contri-

Diante do exposto até aqui, fica evidenciada a dificuldade encontrada pela escola pesquisada para com um trabalho voltado aos alunos ditos “diferenciados”. Para além de pensarmos numa educação voltada 
às diferenças, devemos refletir sobre o racismo e o preconceito instituído no campo da educação, que, pautado no conceito de diversidade, opta por homogeneizar o currículo, a escolarização e seus conteúdos, a partir da negação e da invisibilidade de uma parcela da população em idade escolar, silenciada e desvalorizada há longas décadas na sociedade brasileira.

No intuito de desconstruir tal homogeneização, as lideranças de Bracuí começaram a esboçar uma proposta pedagógica para trabalhar o jongo na escola, que contempla tanto uma parte teórica (a história do jongo, de onde veio, o porquê do jongo e, atrelada a isso, a história da própria comunidade), como uma parte prática propriamente dita (dança, música, canto). Alguns jongueiros da comunidade estariam dispostos a ir até a escola para dar oficinas e, em outros casos, velhos jongueiros, que por conta da idade teriam maior dificuldade de locomoção, poderiam receber os alunos em suas casas e quintais, para falar do jongo e dançá-lo. Tal proposta ainda se encontra em processo de construção, ou seja, ainda não está formalizada, tampouco sistematizada junto à escola. Porém, representa um indicativo positivo de aproximação e diálogo significativos entre escola e comunidade:

Quando o jongo vai pra escola, ele é convidado na época de festa, fes-
ta junina - que esse ano nem teve - festa interna entre escola e aluno,
que foi aberta à comunidade. Tem a festa da escola que é a "Frutos
da Terra". Então assim... quando vai dançar o jongo nessa época de
festa, as pessoas, os alunos, têm muito preconceito com o jongo, não
conhecem o jongo. Então, o jongo entrando na escola é uma forma
dos alunos estarem conhecendo a própria cultura... Muitos quilombo-
las que não moram aqui nessa rua estão conhecendo... E para aqueles
que não são quilombolas também estarem conhecendo. (Liderança
política integrante da Arquisabra, janeiro de 2012)

A demanda da comunidade em relação à escola, que ainda não representa uma proposição concreta, vai para além das iniciativas realizadas até então. Se o jongo estava restrito a apresentações folclóricas, em festas típicas ou em datas comemorativas, agora o foco é inseri-lo num contexto de problematização que combata, de um lado, o racismo, e, de outro, o preconceito, principalmente pelo desconhecimento sobre o que remete à identidade quilombola. Como nos alerta Gomes (2003, p. 77):

No caso específico da educação escolar, ao tentarmos compreender, debater e problematizar a cultura negra, não podemos desconsiderar a existência do racismo e da desigualdade entre negros e brancos em nossa sociedade. Por quê? Porque ao fazermos tal ponderação inevitavelmente nos afastaremos das práticas 


\section{JONGO E CURRÍCULO EM UMA ESCOLA QUILOMBOLA: DIÁLOGOS POSSÍVEIS}

Compreendemos que o currículo se situa para além de um documento que indica as disciplinas e conteúdos curriculares, ou seja, ele representa um documento de identidade, já que reflete as determinações de um grupo social e político. A questão central do currículo remete a quais conhecimentos devem ser ensinados. Logo, o currículo é sempre resultado de uma seleção. As teorias do currículo, ligadas às teorias pedagógicas, devem ser capazes de justificar, a partir da seleção dos conteúdos, o porquê de determinados conhecimentos em detrimento de outros (SILVA, 2010).

Ao longo de dois anos de trabalho de campo (2011 e 2012), fomos percebendo o estreitamento paulatino entre escola e comunidade, isto é, observamos uma abertura para a demanda de inserção do jongo no currículo. Segundo a fala de uma das lideranças da Arquisabra: “a gente tinha pensado várias vezes em fazer isso, mas nunca tivemos uma abertura com a escola, e agora a própria direção chamou a gente pra conversar" (janeiro de 2012). Iniciada essa aproximação por meio do jongo, atualmente, a luta por uma "educação diferenciada" ganhou força na comunidade. Obtivemos recentemente a informação de que, no dia 12 de agosto de 2015, reuniram-se na escola local lideranças políticas, professores, diretores e coordenadores da Áurea Pires da Gama, e gestores da Secretaria Municipal de Educação de Angra dos Reis, para iniciar uma pauta de trabalho coletivo visando à implementação de uma Educação Escolar Quilombola. Vale ressaltar que os desdobramentos desse encontro só poderão ser avaliados a posteriori. Entretanto, um marco fundamental que precisa ser destacado foi a decisão de classificar a escola como quilombola no Censo Escolar, o que, por si só, já representa algum avanço. Foram criados também grupos de trabalho com todos os envolvidos, que deverão construir propostas pedagógicas na perspectiva das demandas quilombolas.

Segundo o Censo Escolar de 2010, existem no Brasil 1.912 escolas localizadas em áreas remanescentes de quilombos. Desse montante, 1.889 são públicas e 23, privadas. Das públicas, 109 são estaduais, 1.779 , municipais e apenas uma é federal. Podemos dizer que foi por meio do jongo que Bracuí iniciou a luta por uma “educação diferenciada”, o que antecedeu inclusive a publicação da política educacional voltada a uma nova modalidade de ensino: as Diretrizes Curriculares Nacionais para a Educação Escolar Quilombola (BRASIL, 2012). Nosso interesse, portanto, é apresentar esse diálogo, não com o intuito de afirmarmos que o 
jongo deve ou não adentrar a escola, mas, em outro formato, objetivando trazer uma reflexão sobre esse debate, que pode vir a iluminar tantos outros debates referentes a esse campo de estudo ainda em construção.

Pesquisas acadêmicas mais recentes vêm se debruçando sobre o tema da chamada "educação diferenciada" em comunidades quilombolas sem, contudo, estarem respaldadas em um conceito comum para tal categoria de educação. Em geral, são retratadas iniciativas isoladas, em que podem ser observadas relações convergentes entre o projeto político da comunidade e a educação formal, ou seja, descrições que apontam para a escola como extensão do projeto político da comunidade.

A pesquisa de mestrado de Silva (2012) aponta para a iniciativa de uma "educação diferenciada" em sua comunidade quilombola de origem, a partir da proposta de pedagogia escolar pautada em processos educativos não formais, situados nas mais variadas formas de organização de Conceição das Crioulas, localizada no sertão do estado de Pernambuco. Já a dissertação de Oliveira (2006) traz uma diferenciação analítica entre a escola no quilombo e a escola do quilombo na comunidade quilombola de Mangal/Barro vermelho, situada no Oeste Baiano. Essa diferenciação demonstra a mudança na relação entre escola e comunidade, a partir da conquista do controle político-pedagógico daquela por parte desta. Os conteúdos escolares que tradicionalmente compõem o currículo proposto foram questionados e transgredidos, mesmo com as barreiras impostas pela política educacional do município.

Atualmente, podemos afirmar que há uma política educacional diferenciada que assegura e legitima o direito da população quilombola a uma escola que respeite e dialogue com os seus valores culturais. Entretanto, o que se observa no campo empírico da nossa pesquisa é que o fato de a instituição de ensino estar localizada em uma comunidade quilombola não assegura um currículo que dialogue com a realidade local. Nesse sentido, uma proposta curricular para uma escola quilombola deverá incorporar saberes tradicionais em articulação com os saberes escolares, sem hierarquização (BRASIL, 2012). Tem-se um grande desafio, portanto, nessa modalidade de ensino, que é o de selecionar e ordenar conhecimentos, considerando a presença de uma constelação de saberes que circulam na, dialogam com e indagam a vida cotidiana de crianças e jovens quilombolas.

A demanda da comunidade de Bracuí pela entrada do jongo no currículo da escola Áurea Pires da Gama, até o momento da pesquisa, não parece representar uma busca por uma "educação diferenciada” se tomarmos como base as pesquisas anteriormente citadas (OLIVEIRA, 2006; SILVA, 2012). Analiticamente, o desejo da comunidade parece estar mais voltado a uma perspectiva de educação multicultural. Como nos lembra Forquin (1993), o multiculturalismo representa a situação de coexistência objetiva de grupos de diferentes origens étnicas, 
geográficas, religiosas, dentre outras. Em relação ao multiculturalismo na educação, o autor assinala que esta só se apresenta multicultural quando faz escolhas pedagógicas que representam, em seus conteúdos e métodos, a diversidade cultural do público ao qual se dirige.

Cumpre destacarmos que a perspectiva multicultural de currículo, no caso da demanda da comunidade de Bracuí, volta-se ao conceito da “diferença”, por enfatizar o processo social de produção da diferença e da identidade, em suas conexões, sobretudo com relações de poder e autoridade, por meio da prática cultural do jongo. Logo, a “educação diferenciada” buscada pelas lideranças políticas não estaria pautada no conceito de diversidade, conceito este mais usualmente conhecido no campo da educação, que estimularia, ao invés do reconhecimento, uma política de tolerância aos saberes tradicionais que envolvem o jongo. Como comenta Candau (2011), o conceito de diversidade tem pouca relevância teórica, sobretudo por seu evidente essencialismo cultural, uma vez que traz implícita a ideia de que a diversidade está dada, que ela pré-existe aos processos sociais pelos quais foi criada. Desse modo, permitir que os alunos quilombolas e não quilombolas conheçam o conjunto de saberes que envolvem o jongo, seus significados, sua importância no contexto de Bracuí como mecanismo de luta por políticas públicas diferenciadas, e o seu papel na reafirmação de um pertencimento étnico torna-se um meio possível de se trabalhar com a diferença no contexto escolar de forma intercultural.

\section{CONSIDERAÇÕES FINAIS}

Dentre algumas questões que nortearam nossa análise, podemos dizer que uma Educação Escolar Quilombola pressupõe, antes de tudo, uma relação dialógica e estreita entre a comunidade escolar e a comunidade quilombola, o que, na prática, é um fato dificilmente observado. Pelo contrário, as relações nesse cenário, em geral, são marcadas por conflitos e embates políticos, muitas vezes arrastados por anos e sem prognósticos positivos. Entretanto, especialmente em nosso campo empírico, percebemos atualmente uma abertura da escola para o trabalho com/junto à comunidade, laço esse estreitado inicialmente pela demanda de inserção do jongo no currículo escolar e, mais recentemente, pela classificação da Áurea Pires da Gama como escola quilombola.

Nesse sentido, o jongo, ao ser inserido na escola, contribui para o autorreconhecimento positivo da identidade quilombola entre jovens e crianças pertencentes a tal grupo étnico, assim como para a valorização de sua cultura local, ao mesmo tempo em que atende a uma educação pautada nas diferenças étnicas, uma vez que traz saberes tradicionais para o conhecimento de alunos não quilombolas.

Por fim, cabe explicitarmos que a comunidade quilombola de Bracuí, ao demandar a inserção do jongo na escola, assim o faz na perspectiva de se 
aproximar desta e, ao mesmo tempo, de se reconhecer na educação formal por meio de sua cultura jongueira. É justamente essa cultura jongueira que auxiliou os moradores no processo de autoatribuição enquanto remanescentes de quilombo. Nesse sentido, fica a questão: o projeto de "educação diferenciada” em cada uma das comunidades quilombolas brasileiras é tão variado quanto as suas próprias histórias e mitos de origem.

\section{REFERÊNCIAS}

ARRUTI, Jose Maurício. Quilombos. In: PINHO, Osmundo; SANSONE, Livio (Org.). Raça: novas perspectivas antropológicas. Salvador: ABA; Edufba, 2008.

ARRUTI, José Maurício. Da “educação do campo” à “educação quilombola”: identidade, conceitos, números, comparações e problemas. Raízes, v. 33, n. 1, p. 164-179, 2011.

ARRUTI, José Maurício; FIGUEIREDO, André Luiz Videira. Processos Cruzados: configuração da questão quilombola e campo jurídico no Rio de Janeiro. Boletim Informativo Nuer, Florianópolis, v. 2, n. 2, p. 73-93, 2005.

BARTH, Fredrik. Os grupos étnicos e suas fronteiras. In: LASK, Tomke (Org.). 0 guru, o iniciador e outras variações antropológicas. Rio de Janeiro: Contra-Capa, 2000. p. 25-67.

BRAGATTO, Sandra. Laudo antropológico da Comunidade Remanescente de Quilombo de Santa Rita do Bracuhy. Parecer n. 004/FCP/MinC, 1999.

BRASIL, Ministério da Educação. Lei Federal n. 10.639 de 9 de janeiro de 2003. Altera a Lei n. 9.394, de 20 de dezembro de 1996, que estabelece as diretrizes e bases da educação nacional, para incluir no currículo oficial da rede de ensino a obrigatoriedade da temática "História e Cultura Africana e Afro-Brasileira”. Brasília, DF, 2003.

BRASIL, Conselho Nacional de Educação. Diretrizes Curriculares Nacionais para a Educação das Relações Étnico-Raciais e para o Ensino de História e Cultura Afro-Brasileira e Africana. Brasília, DF, 2004.

BRASIL, Decreto Federal n. 5.051 de 19 de abril de 2004. Promulga a Convenção n. 169 da Organização Internacional do Trabalho - OIT - sobre Povos Indígenas e Tribais. Brasília, DF: Casa Civil, 2004.

BRASIL, Decreto Federal n. 6.040 de 07 de fevereiro de 2007. Institui a Política Nacional de Desenvolvimento Sustentável dos Povos e Comunidades Tradicionais. Brasília, DF: Casa Civil, 8 ago. 2007.

BRASIL, Ministério da Educação. Resolução n. 4 de 13 de julho de 2010. Fixa as Diretrizes Curriculares Nacionais para o Ensino Fundamental de 9 anos. Brasília, DF, 2010.

BRASIL, Ministério da Educação. Resolução n. 7 de 14 de dezembro de 2010. Fixa as Diretrizes Curriculares Nacionais para o Ensino Fundamental de 9 anos. Brasília, DF: MEC, 2010.

BRASIL, Ministério da Educação. Diretrizes Curriculares Nacionais para a Educação Escolar Quilombola. Brasília, DF: MEC, 2012.

BURKE, Peter. A história como memória social. In: BURKE, Peter. 0 mundo como teatro. Estudos de antropologia histórica. Lisboa: Difel, 1992.

CANDAU, Vera Maria Ferrão. Diferenças culturais, cotidiano escolar e práticas pedagógicas. Currículo sem Fronteiras, v. 11, n. 2, p. 240-255, 2011.

COSTA, Carlos Eduardo. Folia de Reis, a metáfora da migração. A Folia de Reis e a migração de pretos e pardos no pós-abolição: Vale do Paraíba e Baixada Fluminense (1888-1940). In: ABREU, Martha; PEREIRA, Matheus Serva (Org.). Caminhos da liberdade: histórias da abolição e do pós-abolição no Brasil. Niterói: PPGHistória - UFF, 2011. p. 391-413.

FORQUIN, Jean-Claude. Escola e cultura: as bases sociais e epistemológicas do conhecimento escolar. Porto Alegre: Artes Médicas, 1993. 
GEERTZ, Clifford. A interpretação das culturas. Rio de Janeiro: Guanabara Koogan, 1989.

GOHN, Maria da Gloria. Educação não formal e cultura política. Impactos sobre o associativismo do terceiro setor. São Paulo: Cortez, 2011.

GOMES, Nilma Lino. Cultura negra e educação. Revista Brasileira de Educação, São Paulo, n. 23, p. 75-85, 2003.

HALBWACHS, Maurice. A memória coletiva. Rio de Janeiro: Vértice, 1990.

MATTOS, Hebe et al. Relatório antropológico de caracterização histórica, econômica e sócio-cultural do quilombo de Santa Rita do Bracuí. Niterói, RJ: INCRA/SRRJ, UFF/FEC, 2009.

MATTOS, Hebe; ABREU, Martha. Jongo, registros de uma história. In: LARA, Silvia Hunold; PACHECO, Gustavo (Org.). Memória do jongo: as gravações históricas de Stanley J. Stein. Rio de Janeiro: Folha Seca; Campinas, Unicamp/Cecult, 2007. p. 69-106.

MATTOS, Hebe; ABREU, Martha. O mapa do jongo no século XXI e a presença do passado: patrimônio imaterial e a memória da África no antigo sudeste cafeeiro. In: REIS, Daniel Aarão (Org.). Tradições e modernidades. Rio de Janeiro: Editora FGV, 2010. p. 95-113.

MAROUN, Kalyla. Jongo e educação: a construção de uma identidade quilombola a partir de saberes étnico-culturais do corpo. Tese (Doutorado em Educação) - Pontifícia Universidade Católica do Rio de Janeiro, Rio de Janeiro, 2013.

MUNANGA, Kabengele (Org.). Superando o racismo na escola. Brasília: Ministério da Educação, Secretaria de Educação Continuada, 2005.

OLIVEIRA, Sandra Nivea Soares de. De mangazeiros a quilombolas: terra, educação e identidade em Mangal e Barro Vermelho. Dissertação (Mestrado em Educação) - Universidade de Brasília, Brasília, DF, 2006.

PACHECO, Gustavo. Memória por um fio: as gravações históricas de Stanley J. Stein. In: LARA, Silvia Hunold; PACHECO, Gustavo (Org.). Memória do jongo: as gravações históricas de Stanley J. Stein. Rio de Janeiro: Folha Seca; Campinas, Unicamp/Cecult, 2007, p. 15-32.

PASSOS, Mailsa Carla. O jongo, o jogo, a ONG: um estudo etnográfico sobre a transmissão da prática cultural do jongo em dois grupos no Rio de Janeiro. Tese (Doutorado em Educação) Pontifícia Universidade Católica do Rio de Janeiro, Rio de Janeiro, 2004.

PEREZ, Carolina dos Santos Bezerra. Juventude, música e ancestralidade no jongo: som e sentidos no processo identitário. Dissertação (Mestrado em Educação) - Universidade de São Paulo, São Paulo, 2005.

SAHLINS, Marshall. Adeus aos tristes tropos: a etnografia no contexto da moderna história mundial. In: SAHLINS, Marshall. Cultura na prática. Rio de Janeiro: Editora da UFRJ, 2004. p. 503-534.

SILVA, Gilvânia Maria da. Educação como processo de luta política: a experiência de "educação diferenciada” do território quilombola de Conceição das Crioulas. 2012. Dissertação (Mestrado em Educação) - Universidade de Brasília, Brasília, DF, 2012.

SILVA, Tomaz Tadeu da. Documentos de identidade. Uma introdução às teorias do currículo. Belo Horizonte: Autêntica, 2010.

SLENES, Robert. "Eu venho de muito longe, eu venho cavando": jongueiros cumba na senzala centro-africana. In: LARA, Silvia Hunold; PACHECO, Gustavo (Org.). Memória do jongo: as gravações históricas de Stanley J. Stein. Vassouras, 1949. Rio de Janeiro; Campinas, SP: Folha Seca; Unicamp/Cecult, 2007. p. 109-156.

\section{KALYLA MAROUN}

Professora da Faculdade de Educação da Universidade Federal do Rio de Janeiro - UFRJ -, Rio de Janeiro, Rio de Janeiro, Brasil kalylamaroun@gmail.com 